\title{
Deformation of the palate in preterm infants
}

\author{
Annie M Procter, Diane Lether, Richard G Oliver, Patrick HT Cartlidge
}

\begin{abstract}
Aim-To investigate the effect of gestation, postmenstrual age, and orotracheal intubation on palate morphology.

Methods-A prospective study was made of 76 newborn infants of 25 to 41 weeks' gestation. Palate dimensions were measured on plaster models produced from serial palatal impressions. Palate size relative to that of the mouth was assessed using a ratio of palate depth to palate width (Palatal Index).

Results-Palate depth and width were related to postmenstrual age and gestation. Palatal Index ranged from 0.15 to 0.57 , indicating a wide variation in palate shape, but gestation and postmenstrual age had no effect. Prolonged intubation had a small effect, equivalent to an increase in palatal depth of less than $2 \mathrm{~mm}$ at 32 weeks' postmenstrual age. The effect was transient.

Conclusion-Prolonged orotracheal intubation ( $>10$ days) leads to a small and temporary increase in palatal depth. However, this is unlikely to account for palatal grooving, which is probably caused by an overgrowth of the lateral palatine ridges. (Arch Dis Child Fetal Neonatal Ed 1998;78:F29-F32)
\end{abstract}

Keywords: palate; deformation; orotracheal intubation

Deformations occur as a result of an imbalance in mechanical forces acting on malleable tissues. Uterine constraint in the fetus may lead to congenital dislocation of the hip, and in more extreme situations, severe and chronic oligohydramnios may precipitate deformation. In newborn infants gravity is the most obvious deforming force. Side to side flattening of the head occurs in many preterm infants if they lie with it to one side, because the skull bones are thin and soft and the infant relatively immobile. ${ }^{1}$ Similarly, postnatal moulding of the lower limb with external rotation of the hip and torsion of the rest of the leg and ankle occurs due to prolonged lying in a frog leg position. ${ }^{2}{ }^{3}$ Specific interventions such as changes in posture or the use of a soft mattress can reduce postnatal moulding, and deformations also improve in early childhood with the passage of time. $^{45}$

Palatal grooving has been described in $17 \%$ to $87 \%$ of preterm infants. ${ }^{67}$ The association with extreme prematurity has led to the suggestion that it is an oral manifestation of the head flattening commonly seen in very premature infants. ${ }^{8}$ An alternative hypothesis, supported by the association with prolonged orotracheal intubation, is that the deformation results from the continuous pressure of the endotracheal tube against the median palatine suture. ${ }^{910}$ If these explanations are correct, then the depth of the palate should be greatest in extremely preterm infants, and after prolonged intubation. In this study we measured the palate in full term and preterm infants to determine the effect of gestation, postmenstrual age, and intubation on palate morphology.

\section{Methods}

Seventy six neonates were included in the study. Their gestational age ranged from 25 to 41 weeks (median 33 weeks), and birthweight 715 to $4730 \mathrm{~g}$ (median $1880 \mathrm{~g}$ ). They were divided into three groups according to their gestation; 27 infants were less than 32 weeks of gestation, 29 were 32 to 35 weeks' gestation, and 20 were 36 weeks' gestation or more. Measurements were made on each infant during the first five days of life, and where possible at $28,32,36,40,53,66$, and 92 weeks of postmenstrual age. Twenty three infants were ventilated for between 1 and 32 days, using an oral endotracheal tube (Portex Blue Line). Twenty one of these infants had a gestational age of less than 32 weeks; 19 were intubated for less than 10 days, and four for 10 days or more. Two infants with a gestational age of 32 to 35 weeks were intubated, both for less than 10 days; no infants in the most mature group were intubated. Infants requiring intensive care were usually nursed prone, and at other times they were mostly supine. Nasogastric tubes were used for delivering lavage feeds.

A mould of the palate and maxillary alveolar ridges (gum pads) was obtained from a maxillary impression using vinylpolysiloxone impression material (Elite Fast) loaded on to a specially designed dental tray. The mould was then cast in a stone hard plaster to provide a model of the palate and alveolar ridges from which measurements were made. Each palate model had key landmarks identified (fig 1) to allow the accurate and comparable measurement of palate depth (distance B-E) and palate width (distance $\mathrm{C}-\mathrm{D}$ ). The deepest point in the midline of the palate (point B) relative to the crest of the alveolar gum pads, and the midline point on the anterior crest of the alveolar gum pad ridge (point $A$ ) were identified by visual inspection. Points $\mathrm{C}$ and $\mathrm{D}$ on the lateral alveolar ridges were perpendicular to line $\mathrm{A}-\mathrm{B}$ in the coronal plane at the level of the deepest point (point B). Accurate identification of points C and $\mathrm{D}$ required that the model be held in a specially constructed spring loaded deck (fig 2). The upper plate of the deck was transparent perspex and rested on the alveolar crestal margins. It had $0.5 \mathrm{~mm}$ holes drilled at $3 \mathrm{~mm}$ intervals along the sagittal and coronal planes. The 


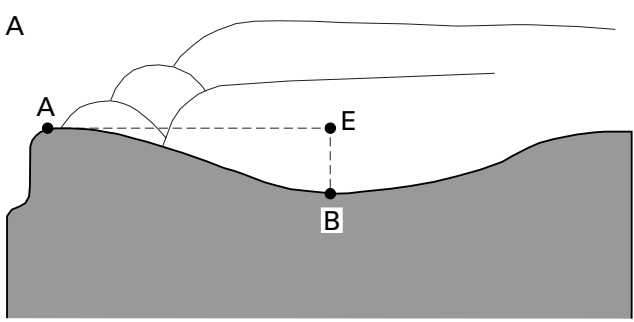

Cross-section through palate model

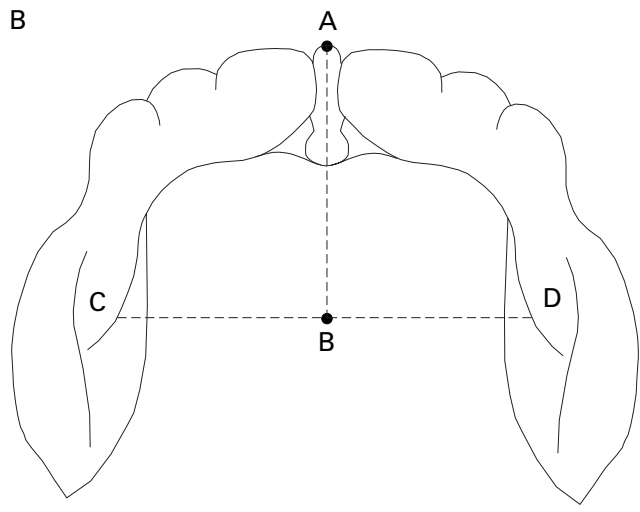

Figure 1 Palate model viewed from above.

hole at the intersection of the planes was aligned perpendicular to the deepest point (point B) using a $0.5 \mathrm{~mm}$ pencil lead (Pentel Super Hi Polymer) inserted through the hole vertically on to point $\mathrm{B}$. By aligning the holes in the sagittal plane of the deck with the midpoint of the alveolar ridge (point $\mathrm{A}$ ), the coronal plane on the palate model was marked and the points $\mathrm{C}$ and $\mathrm{D}$ on the lateral alveolar margins identified. The dimensions of the palate model were measured using a high precision reflex microscope which identified the $\mathrm{x}, \mathrm{y}$, and $\mathrm{z}$ coordinates of a given point with a resolution of $0.2 \mathrm{~m}$. The coordinates of the deepest point (point B), and the midpoint of line $\mathrm{C}-\mathrm{D}$ (coordinate $\mathrm{E}$ ), were used to measure the palate depth (distance $\mathrm{B}-\mathrm{E})$. The palate width was the distance between points $\mathrm{C}$ and $\mathrm{D}$.

As has been found elsewhere, ${ }^{11}{ }^{12}$ tooth eruption was delayed in our sample of premature infants. The presence of teeth on models from the 66 and 92 week records was not a problem in most cases. Where teeth had erupted, a point on the gingival margin between the incisors was used as Point $\mathrm{A}$.

The size of the oral cavity varies considerably with gestation and postnatal age. To assess the depth of the palate relative to the size of the mouth, the Palatal Index, a ratio of palate depth

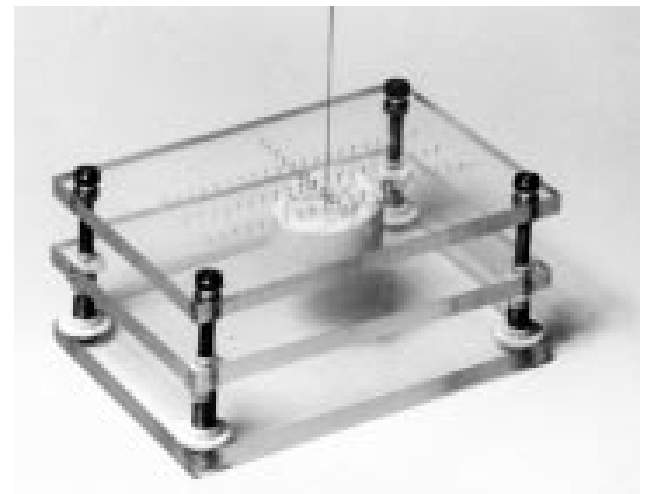

Figure 2 Palate model plus pencil lead in spring loaded deck.

to palate width (BE/CD),$^{13}$ was calculated. The greater the value of the Palatal Index, the deeper the palate relative to the size of the mouth. Similarly, the shape of the head was assessed using the Cranial Index, a ratio of the occipito-frontal diameter to the biparietal diameter. ${ }^{1}$ The greater the Cranial Index, the flatter the head. All measurements were carried out by one investigator.

The study was approved by the local ethics committee and written parental consent obtained.

\section{Results}

There were 267 impressions attempted. In 10 cases the impression could not be obtained due to non-compliance, and in 40 the model was unsuitable because landmarks could not be clearly identified. Two hundred and seventeen palatal models from 76 subjects were therefore included in the study.

Overall, palate depth increased with postmenstrual age, from a mean $(95 \%$ confidence interval) of $6.20 \mathrm{~mm}(5.49-6.91)$ at 28 weeks to $9.34 \mathrm{~mm}(9.05-9.63)$ at 53 weeks of postmenstrual age (table 1). Thereafter palate depth remained relatively constant, with a mean of $9.24 \mathrm{~mm}(8.57-9.91)$ at 66 weeks, and $9.37 \mathrm{~mm}(8.78-9.96)$ at 92 weeks of postmenstrual age. Palate width increased from a mean of $20.93 \mathrm{~mm}(19.66-22.20)$ at 28 weeks of postmenstrual age, to $31.20 \mathrm{~mm} \mathrm{(30.24-}$ $32.16)$ at 53 weeks, and thereafter increased more gradually to $33.80 \mathrm{~mm}(32.76-34.84)$ at 92 weeks of postmenstrual age.

Palate depth tended to be greatest in the more mature infants at similar postmenstrual ages, although the differences at individual ages were not significant (table 2). Thus, at 36 weeks of postmenstrual age, infants less than 32 weeks of gestation had a mean palate depth

Table 1 Palate dimensions according to postmenstrual age (mean (SEM))

\begin{tabular}{|c|c|c|c|c|c|c|c|}
\hline & \multicolumn{7}{|c|}{ Postmenstrual age (weeks) } \\
\hline & 28 & 32 & 36 & 40 & 53 & 66 & 92 \\
\hline $\begin{array}{l}\text { Palate depth } \\
\quad(\mathrm{mm})\end{array}$ & $\begin{array}{l}6.20(0.36) \\
n=19\end{array}$ & $\begin{array}{l}6.84(0.18) \\
n=42\end{array}$ & $\begin{array}{l}7.44(0.18) \\
\mathrm{n}=37\end{array}$ & $\begin{array}{l}8.17(0.21) \\
\mathrm{n}=35\end{array}$ & $\begin{array}{l}9.34(0.15) \\
\mathrm{n}=27\end{array}$ & $\begin{array}{l}9.24(0.34) \\
\mathrm{n}=27\end{array}$ & $\begin{array}{l}9.37(0.30) \\
\mathrm{n}=27\end{array}$ \\
\hline $\begin{array}{l}\text { Palate width } \\
\text { (mm) }\end{array}$ & $\begin{array}{l}20.93(0.65) \\
n=19\end{array}$ & $\begin{array}{l}23.38(0.46) \\
\mathrm{n}=42\end{array}$ & $\begin{array}{l}25.79(0.46) \\
\mathrm{n}=36\end{array}$ & $\begin{array}{l}28.28(0.42) \\
\mathrm{n}=34\end{array}$ & $\begin{array}{l}31.20(0.49) \\
\mathrm{n}=26\end{array}$ & $\begin{array}{l}32.16(0.54) \\
\mathrm{n}=28\end{array}$ & $\begin{array}{l}33.80(0.53) \\
\mathrm{n}=28\end{array}$ \\
\hline Palatal index & $\begin{array}{l}0.30(0.02) \\
n=19\end{array}$ & $\begin{array}{l}0.30(0.01) \\
\mathrm{n}=41\end{array}$ & $\begin{array}{l}0.29(0.01) \\
\mathrm{n}=36\end{array}$ & $\begin{array}{l}0.29(0.01) \\
\mathrm{n}=34\end{array}$ & $\begin{array}{l}0.30(0.01) \\
\mathrm{n}=26\end{array}$ & $\begin{array}{l}0.29(0.01) \\
\mathrm{n}=27\end{array}$ & $\begin{array}{l}0.28(0.01) \\
\mathrm{n}=27\end{array}$ \\
\hline
\end{tabular}


Table 2 Palate depth and palate width according to postmenstrual and gestational age (mean (SEM))

\begin{tabular}{|c|c|c|c|c|c|c|c|}
\hline \multirow[b]{2}{*}{ Palate } & \multicolumn{7}{|c|}{ Postmenstrual age (weeks) } \\
\hline & 28 & 32 & 36 & 40 & 53 & 66 & 92 \\
\hline \multicolumn{8}{|c|}{$<32$ weeks gestation } \\
\hline Depth (mm) & $\begin{array}{l}6.20(0.36) \\
n=19\end{array}$ & $\begin{array}{l}6.37(0.23) \\
n=23\end{array}$ & $\begin{array}{l}7.05(0.23) \\
\mathrm{n}=15\end{array}$ & $\begin{array}{l}7.42(0.36) \\
\mathrm{n}=12\end{array}$ & $\begin{array}{l}9.00(0.15) \\
\mathrm{n}=9\end{array}$ & $\begin{array}{l}8.82(0.76) \\
n=10\end{array}$ & $\begin{array}{l}9.13(0.62) \\
\mathrm{n}=10\end{array}$ \\
\hline Width (mm) & $\begin{array}{l}20.93(0.65) \\
n=19\end{array}$ & $\begin{array}{l}21.81 \\
\mathrm{n}=23\end{array}$ & $\begin{array}{l}24.15(0.74) \\
\mathrm{n}=15\end{array}$ & $\begin{array}{l}27.06(0.61) \\
\mathrm{n}=12\end{array}$ & $\begin{array}{l}29.42(0.91) \\
\mathrm{n}=8\end{array}$ & $\begin{array}{l}30.85(0.85) \\
\mathrm{n}=10\end{array}$ & $\begin{array}{l}33.77(0.88) \\
\mathrm{n}=10\end{array}$ \\
\hline \multicolumn{8}{|c|}{ 32-35 weeks gestation } \\
\hline Depth (mm) & & $\begin{array}{l}7.41(0.22) \\
\mathrm{n}=19\end{array}$ & $\begin{array}{l}7.70(0.36) \\
\mathrm{n}=13\end{array}$ & $\begin{array}{l}8.71(0.44) \\
\mathrm{n}=11\end{array}$ & $\begin{array}{l}9.35(0.36) \\
\mathrm{n}=8\end{array}$ & $\begin{array}{l}9.05(0.58) \\
n=8\end{array}$ & $\begin{array}{l}9.39(0.34) \\
\mathrm{n}=7\end{array}$ \\
\hline Width (mm) & & $\begin{array}{l}25.27(0.50) \\
\mathrm{n}=19\end{array}$ & $\begin{array}{l}27.42(0.57) \\
\mathrm{n}=12\end{array}$ & $\begin{array}{l}30.03(0.54) \\
\mathrm{n}=10\end{array}$ & $\begin{array}{l}32.77(0.29) \\
\mathrm{n}=8\end{array}$ & $\begin{array}{l}32.80(0.70) \\
\mathrm{n}=9\end{array}$ & $\begin{array}{l}34.01(0.89) \\
\mathrm{n}=8\end{array}$ \\
\hline \multicolumn{8}{|c|}{$>35$ weeks gestation } \\
\hline Depth (mm) & & & $\begin{array}{l}7.71(0.30) \\
\mathrm{n}=9\end{array}$ & $\begin{array}{l}8.42(0.27) \\
\mathrm{n}=12\end{array}$ & $\begin{array}{l}9.64(0.25) \\
\mathrm{n}=10\end{array}$ & $\begin{array}{l}9.71(0.25) \\
n=9\end{array}$ & $\begin{array}{l}10.02(0.30) \\
\mathrm{n}=10\end{array}$ \\
\hline Width (mm) & & & $\begin{array}{l}26.37(0.66) \\
n=9\end{array}$ & $\begin{array}{l}28.05(0.73) \\
\mathrm{n}=12\end{array}$ & $\begin{array}{l}31.38(0.80) \\
\mathrm{n}=10\end{array}$ & $\begin{array}{l}32.98(1.13) \\
\mathrm{n}=9\end{array}$ & $\begin{array}{l}33.92(1.02) \\
\mathrm{n}=10\end{array}$ \\
\hline
\end{tabular}

Table 3 Palatal Index and Cranial Index according to postmenstrual and gestational age (mean (SEM))

\begin{tabular}{|c|c|c|c|c|c|c|c|}
\hline & \multicolumn{7}{|c|}{ Postmenstrual age (weeks) } \\
\hline & 28 & 32 & 36 & 40 & 53 & 66 & 92 \\
\hline \multicolumn{8}{|l|}{$<32$ weeks gestation } \\
\hline Palatal index & $0.30(0.02)$ & $0.30(0.01)$ & $0.30(0.01)$ & $0.28(0.02)$ & $0.31(0.01)$ & $0.28(0.02)$ & $0.27(0.02)$ \\
\hline Cranial index & $1.42 \mathrm{n}=19$ & $1.57 \mathrm{n}=23$ & $1.58 \mathrm{n}=15$ & $1.48 \mathrm{n}=12$ & $1.29 \mathrm{n}=8$ & $1.31 \mathrm{n}=10$ & $1.31 \mathrm{n}=10$ \\
\hline \multicolumn{8}{|c|}{ 32-35 weeks gestation } \\
\hline Palatal index & & $0.29(0.01)$ & $0.28(0.01)$ & $0.29(0.01)$ & $0.28(0.01)$ & $0.27(0.01)$ & $0.28(0.02)$ \\
\hline Cranial index & & $1.47 \mathrm{n}=18$ & $1.49 \mathrm{n}=12$ & $1.38 n=10$ & $1.29 \mathrm{n}=8$ & $1.29 n=8$ & $1.3 \mathrm{n}=7$ \\
\hline \multicolumn{8}{|l|}{$>35$ weeks gestation } \\
\hline Palatal index & & & $0.29(0.02)$ & $0.30(0.01)$ & $0.31(0.01)$ & $0.30(0.01)$ & $0.30(0.01)$ \\
\hline Cranial index & & & $1.33 n=9$ & $1.3 \mathrm{n}=12$ & $1.31 \mathrm{n}=10$ & $1.29 \mathrm{n}=9$ & $1.3 \mathrm{n}=10$ \\
\hline
\end{tabular}

Table 4 Effect of orotracheal intubation on Palatal Index (mean (SEM))

\begin{tabular}{|c|c|c|c|c|c|c|c|}
\hline \multirow[b]{2}{*}{ Duration of intubation } & \multicolumn{7}{|c|}{ Postmenstrual age (weeks) } \\
\hline & 28 & 32 & 36 & 40 & 53 & 66 & 92 \\
\hline \multicolumn{8}{|l|}{ None } \\
\hline $\begin{array}{l}\text { Palatal index } \\
1-9 \text { days }\end{array}$ & $0.27 \mathrm{n}=3$ & $0.29 \mathrm{n}=23$ & $0.29 n=23$ & $0.30 n=23$ & $0.29 \mathrm{n}=18$ & $0.29 n=19$ & $0.28 n=19$ \\
\hline Palatal index & $0.31 \mathrm{n}=13$ & $0.28 n=15$ & $0.27 n=10$ & $0.27 \mathrm{n}=9$ & $0.31 \mathrm{n}=7$ & $0.27 n=6$ & $0.28 \mathrm{n}=7$ \\
\hline$\geqslant 10$ days & & & & & & & \\
\hline Palatal index & $0.29 \mathrm{n}=3$ & $0.37 \mathrm{n}=3$ & $0.35 n=3$ & $0.28 \mathrm{n}=2$ & $0.37 n=1$ & $0.26 \mathrm{n}=2$ & $0.25 \mathrm{n}=1$ \\
\hline
\end{tabular}

of $7.05 \mathrm{~mm}$ (6.60-7.50), compared with $7.71 \mathrm{~mm}(7.12-8.30)$ in infants more than 35 weeks of gestation. At 53 weeks of postmenstrual age the palate depth in these gestational age groups was $9.00 \mathrm{~mm}(8.71-9.29)$ and 9.64 $\mathrm{mm}$ (9.15-10.13), respectively, and at 92 weeks it was $9.13 \mathrm{~mm}(7.91-10.35)$ and 10.02 $\mathrm{mm}$ (9.43-10.61); infants of 32 to 35 weeks of gestation had intermediate values. Palate width also tended to be greater in the more mature infants at the same postmenstrual age but this was not significant (table 2). The rate of increase in palate depth and palate width with postmenstrual age was similar in each gestational age group.

Overall, Palatal Index ranged from 0.15 to 0.57 (mean 0.29), indicating a wide individual variation in the shape of the palate. However, gestation and postmenstrual age had no effect on Palatal Index. Thus in infants less than 32 weeks of gestation, the mean Palatal Index ranged from $0.30(0.26-0.34)$ at 28 weeks of postmenstrual age, to $0.27(0.23-0.31)$ at 92 weeks (table 3). Similarly, at 32 to 35 weeks of gestation the mean Palatal Index at different postmenstrual ages ranged from 0.27 to 0.29 , and in infants of more than 35 weeks' gestation it ranged from 0.29 to 0.31 . Cranial Index was greatest in the most premature infants up to 53 weeks of postmenstrual age, confirming that these infants tend to have side to side head flattening (table 3). However, there was a low and non-significant correlation between Palatal Index and Cranial Index $(r=-0.03, p=0.7)$.

Prolonged intubation had a transient effect on Palatal Index. At 28 weeks of postmenstrual age the mean Palatal Index in infants intubated for 10 days or more $(0.29)$ was similar to that in non-intubated infants (0.27), and to infants intubated for less than 10 days (0.31) (table 4). By contrast, at 32 weeks and 36 weeks of postmenstrual age the mean Palatal Index in infants intubated for 10 days or more had risen to $0.37(0.35-0.41)$ and $0.35(0.33-0.36)$, respectively, compared with $0.29(0.20-0.49)$ and $0.28(0.15-0.41)$ in non-intubated infants. This is equivalent to a difference in palate depth of $1.9 \mathrm{~mm}$ at 32 weeks of gestation. This difference disappeared at 40 weeks of postmenstrual age and thereafter Palatal Index was similar in intubated and non-intubated infants.

\section{Discussion}

We have described the dimensions of the palate during infancy of babies born at full term and prematurely. The depth and width of the palate were related to gestation and postmenstrual age, with the most mature babies having the 
largest palates. To permit comparison of the palate shape in infants at different gestational and postmenstrual ages, we therefore used the ratio of palate depth to width (Palatal Index). ${ }^{13}$ We found that although there was considerable individual variation in palatal index, it was not related to gestation or postmenstrual age. The shape of the palate in our study was very similar to that reported in 1921 by Denzer in a study of (presumably full term) infants between 1 and 11 months of age; the Palatal Index in that study was $0.28 .^{13}$

Ash and Moss have suggested that a narrow high vaulted palate may be an oral manifestation of head flattening seen in some preterm babies. ${ }^{8}$ Head flattening is most pronounced in very preterm infants during the first few months of life and gets less thereafter. ${ }^{1}$ Palatal shape in our study did not mirror this pattern and furthermore there was a poor correlation between Cranial Index and Palatal Index. We conclude that the external pressure on the side of the head which causes head flattening does not contribute to palatal grooving.

Prolonged intubation ( $\geqslant 10$ days) was the only factor that was associated with an increase in Palatal Index. This was probably due to the direct pressure of the orotracheal tube on the median palatine suture causing it to deform. This was consistent with the finding of Ash and Moss, who also suggested that the deformation can be lessened by the use of an intraoral protective plate. ${ }^{8}$ However, the mean difference in palate depths at 32 weeks between the protected and unprotected palates in Ash and Moss's study was $0.21 \mathrm{~mm}$. Whereas in our group, the mean difference in palatal depth at 32 weeks between the intubated infants and the non-intubated infants was $0.35 \mathrm{~mm}$. This suggests that a plate has minimal protective value. Our study found that by 40 weeks the change in Palatal Index, evident at 32 and 36 weeks in the infants intubated for 10 days or more, had disappeared, showing that the effect of prolonged intubation on palatal morphology is small and transient.

Previous publications have usually described palatal grooves visually rather than giving dimensions. For instance, Erenberg, who reported grooving in $47.6 \%$ of a predominantly premature cohort of infants who had required orotracheal intubation, defined a groove as a "narrow channel of variable depth located near the midline of the palate." In many cases grooving was striking and has been reported to persist into early childhood. ${ }^{14}{ }^{15}$ Despite differences in definition, it seems most unlikely this degree of grooving is caused only by the modest (and transient) elevation of the palate found in our study.

Visual inspection of the palate models in our study revealed that palatal grooving did not always correspond with relative palatal depth, but did usually occur in intubated infants. We therefore consider that palatal grooving is not caused by the direct pressure of the orotracheal tube. It is more likely that grooving is due to overgrowth of the lateral palatine ridges. ${ }^{16}{ }^{17}$ This may be due to irritation by the orotracheal tube, or because normal resting tongue posture against the palatal vault is limited by the orotracheal tube. ${ }^{18}$

We are grateful to the laboratory staff in the University of Wales Dental Hospital for their assistance, and to Dr F Dunstan for statistical advice. The project was funded by the Welsh Scheme for the Development of Health and Social Research.

1 Cartlidge PHT, Rutter N. Reduction of head flattening in preterm infants. Arch Dis Child 1988; 63:755-7.

2 Davis PM, Robinson R, Harris L, Cartlidge PHT. Persistent mild hip deformation in preterm infants. Arch Dis Child 1993;69:597-8

3 Lacey JL, Henderson-Smart DJ, Edwards DA, et al. A longitudinal study of early leg postures of preterm infants. Dev Med Child Neurol 1990;32:151-63.

4 Downs JA, Edwards DA, McCormick DC, Roth SC, Stewart AL. The effect of postural interventions on the development of the hip posture in preterm babies $<33$ weeks gestation. Neonatal Society, 1990. Early Hum Dev 1990;22:171.

5 Rutter N, Hinchcliffe W, Cartlidge PHT. Do preterm infants always have flattened heads? Arch Dis Child 1993; 68:606-7.

6 Erenberg A, Nowak AJ. Palatal groove formation in neonates and infants with orotracheal tubes. Am $\mathcal{F}$ Dis Child 1984;138:974-5.

7 Monteli RA, Bumstead DH. Development and severity of palatal grooves in orally intubated newborns. Am $\mathcal{F}$ Dis Child 1986;140:357-9

8 Ash SP, Moss JP. An investigation of the features of the preterm infant palate and the effect of prolonged orotracheal Ophthalmol 1987; 14: 253-61.

9 Saunders BS, Easa D, Slaughter RJ. Acquired palatal groove in neonates. $\mathcal{F}$ Pediatr 1976;89:988-9.

10 Duke PM, Coulson JD, Santos JL, Johnson JD. Cleft palate associated with prolonged orotracheal intubation in associated with prolonged or

11 Fadavi S, Punwani IC, Adeni S, Vidyasager D. Eruption pattern in the primary dentition of premature low-birthweight children. Fournal of Dentistry for Children 1992;59:120-2.

12 Viscardi RM, Romberg E, Abrams RG. Delayed primary tooth eruption in premature infants: relationship to neonatal factors. Pediatric Dentistry 1994;16: 23-8.

13 Denzer BS. The size of the infantile palate. Am $\mathcal{f}$ Dis Child 1921;22:471-6.

14 Watterberg K, Munsick-Bruno G. Incidence and persistence of acquired palatal groove in preterm neonates following prolonged orotracheal intubation. Clin Res 1986;34: 113A.

15 Warwick-Brown MM. Neonatal palatal deformity following oral intubation. Br Dent f 1987;162: 258-9.

16 Behrstock B, Ramos A, Kaufman N. Does prolonged oral intubation contribute to medial hypertrophy of the lateral palatine ridges and possibly to iatrogenic cleft palate? $\mathcal{f}$ Pediatr 1978; 91:171.

17 Carrillo PJ. Palatal groove formation and oral endotracheal intubation. Am $\mathcal{F}$ Dis Child 1985;139: 859-60.

18 Hanson JW, Smith DW, Cohen MM. Prominent lateral palatine ridges: development and clinical relevance. $\mathcal{F}$ Pediatr 1976;89:54-8. 